\title{
Intrathecal carbachol and clonidine produce a syn- ergistic antiallodynic effect in rats with a nerve lig- ation injury
}

\author{
[L'administration intrathécale de carbachol et de clonidine produit un effet \\ antiallodynique synergique chez des rats présentant une ligature nerveuse]
}

Eun-Ju Lee MD, Ji-Yeon Sim MD, Jong-Yeon Park MD, Jai-Hyun Hwang MD, Pyung-Hwan Park MD, Sung-Min Han MD

Purpose: Antiallodynic effects have been demonstrated after intrathecal administration of -2 adrenoceptor agonists and cholinesterase inhibitors in rats. Intrathecal carbachol also increases the activity of cholinergic receptor system at the spinal level. However, there is no study regarding the antagonism of carbachol on touch-evoked allodynia and the interaction with clonidine. This study examines the intrathecal interaction between two drugs in a rat model of nerve ligation injury.

Methods: Rats were prepared with tight ligation of the left L5-6 spinal nerves and chronic intrathecal catheter implantation. Tactile allodynia was measured by using application of von Frey filaments to the lesioned hindpaw. Carbachol $(0.3-10 \mu \mathrm{g})$ and clonidine ( $1-30 \mu \mathrm{g})$ were administered to obtain the dose-response curves and the $50 \%$ effective dose $\left(E D_{50}\right)$ for each drug. Fractions of $E D_{50}$ values $(1 / 2,1 / 4,1 / 8$, and $1 / 16)$ were administered intrathecally to establish the $\mathrm{ED}_{50}$ of the carbachol-clonidine combination. Isobolographic and fractional analyses of drug interaction were performed.

Results: Intrathecal carbachol and clonidine alone produced a dose-dependent reduction of tactile allodynia without severe motor weakness or sedation. A carbachol-clonidine combination produced a dose-dependent increase in withdrawal threshold of the lesioned hindpaw with a reduced incidence and magnitude of side effects. Both analyses revealed a synergistic interaction after the coadministration of carbachol and clonidine.

Conclusions: This study indicates that carbachol, like clonidine, provides a moderate antagonism on touch-evoked allodynia at the spinal level. The results suggest that intrathecally administered carbachol is synergistic when combined with clonidine.
Objectif : Des effets antiallodyniques ont été mis en évidence à la suite de l'administration intrathécale d'agonistes d' -2 adrénergique et d'inhibiteurs de la cholinestérase chez des rats. L'administration intrathécale de carbachol augmente aussi l'activité du système récepteur cholinergique au niveau rachidien. Cependant, il n'existe pas d'étude sur l'antagonisme du carbachol sur l'allodynie déclenchée par le toucher, ni sur l'interaction avec la clonidine. La présente étude vérifie l'interaction intrathécale de deux médicaments sur un modèle de lésion par ligature nerveuse chez le rat.

Méthode : Les rats ont été préparés par une ligature serrée des nerfs rachidiens gauches à L5-6 et l'implantation d'un cathéter intrathécal à demeure. L'allodynie tactile a été mesurée par l'application de filaments de von Frey sur la patte arrière lésée. On a administré du carbachol $(0,3-10 \mu g)$ et de la clonidine $(1-30 \mu g)$ et obtenu des courbes dose-réponse et la dose efficace $50 \%\left(D E_{50}\right)$ pour chaque médicament. L'administration de fractions de $D E_{50}(1 / 2,1 / 4,1 / 8$ et 1/l6) par voie intrathécale a permis d'établir la $D E_{50}$ de la combinaison de carbachol et de clonidine. Des analyses isobolographiques et fractionnelle de l'interaction médicamenteuse ont été réalisées.

Résultats : Le carbachol et la clonidine employés seuls ont produit un réduction de l'allodynie tactile dépendante de la dose sans faiblesse motrice ou sédation importante. Une combinaison des deux médicaments a fait augmenter la valeur seuil du retrait de la patte lésée, en fonction de la dose, et une réduction de l'incidence et de l'importance des effets secondaires. Les deux analyses ont révélé une interaction synergique après la co-administration de carbachol et de clonidine.

Conclusion: Cette étude montre que le carbachol, comme la clonidine, fournit un antagonisme modéré à l'allodynie tactile au niveau rachidien. Les résultats laissent croire à l'action synergique d'une combinaison de carbachol et de clonidine intrathécaux.

From the Department of Anaesthesiology, University of Ulsan, College of Medicine, Asan Medical Center, Seoul, Korea.

Address correspondence to: Dr. Jai-Hyun Hwang, Department of Anaesthesiology, Asan Medical Center, 388-1 Pungnap-Dong, Songpa-

Ku, Seoul 138-736, Korea. Phone: 8222224 3859; Fax: 822470 1363; E-mail: jhhwang@amc.seoul.kr

Accepted for publication August 27, 2001.

Revision accepted November 5, 2001.

CAN J ANESTH 2002/49:2/pp 178-184 
A peripheral nerve injury may result in a condition of extreme cutaneous sensitivity to normally innocuous mechanical stimuli, designated tactile allodynia. In rats, unilateral ligation of L5 and L6 spinal nerves has been shown to produce signs that appear representative of neuropathic pain. ${ }^{1,2}$ Signs of tactile allodynia were most evident in the nerve ligation model among several experimental animal models. ${ }^{3}$ After injury, these animals displayed a profound and long-lasting tactile allodynia, which was abolished by sympathectomy. ${ }^{4} 5$ The spinal pharmacology of this nerve injury-induced allodynia is distinct from that associated with acute nociceptive input. Clonidine, generally considered a postsynaptic -2 adrenoceptor agonist, has been reported to produce antiallodynia after intrathecal (IT) administration in rats with nerve ligation injury. ${ }^{6,7}$ IT administration of cholinesterase inhibitors displays a dose-dependent antiallodynic effect, which is mediated by the spinal muscarinic receptor system. ${ }^{8}$ Carbachol is a nonspecific cholinergic agonist with a prominent muscarinic effect. ${ }^{9}$ Owing to the hydrophilic properties of carbachol it may have a long duration of action after IT administration. IT carbachol produces consistent analgesia in animals without any appreciable adverse effects. ${ }^{10,11}$ Little is known about the ability of carbachol to provide antiallodynia in rats with nerve ligation injury. Although the synergistic antinociceptive interaction of spinal carbachol with clonidine is demonstrated in normal rats, ${ }^{1}$ there is no study on the antiallodynic interaction in the neuropathic pain model. Therefore, the present study was designed to investigate the antiallodynic effect of carbachol and its possible interaction with clonidine in the rat model of nerve ligation injury.

Methods

\section{Animal preparation}

The investigations were performed under a protocol approved by our Animal Care Committee. The experiments were conducted in male Sprague Dawley rats (weight 160-180 g; Asan LSI, Seoul, Korea), which were housed individually in a temperature controlled $\left(21 \pm 1^{\circ} \mathrm{C}\right)$ vivarium and allowed to acclimate for three days in a 12/12-hr light/dark cycle.

\section{Surgical preparation}

To create the neuropathic rat model, surgery was performed according to the method devised by Kim and Chung. ${ }^{1}$ Under halothane anesthesia, a dorsal midline incision was made from L3 to S2. The left L6/S1 posterior interarticular process was exposed and resected. The L6 transverse process was excised partially and the left L5 and L6 spinal nerves were gently isolated and ligated tightly with 6-0 black silk distal to the dorsal root ganglion and proximal to the formation of the sciatic nerve. Implantation of an IT catheter was performed if the rat showed a withdrawal threshold of 4.0 $\mathrm{g}$ or less by postoperative day seven. Such rats were defined as demonstrating tactile allodynia.

Catheters were implanted chronically, as described previously, for spinal drug administration. ${ }^{12}$ Under halothane anesthesia, the rats were placed in a stereotaxic head holder. The occipital muscles were separated from their attachment points and retracted caudally to expose the cisternal membrane at the base of the skull. IT catheters (PE-10 polyethylene tubing) were passed caudally from the cisterna magna to the spinal cord level of lumbar enlargement. The catheter was externalized through the skin. Only animals with no evidence of neurologic deficit after the operation were studied.

All the pharmacologic experiments were conducted three weeks after spinal nerve ligation because tactile allodynia usually develops within one week after surgery and lasts for six to eight weeks. After checking the baseline value, we conducted the behavioural test in rats displaying allodynia. Studies should be conducted at the same time interval (usually within four to five weeks after spinal nerve ligation) for each intervention. A recovery period of at least five days was allowed before the animals were used in experiments. The animals were ten to 12 weeks of age at the time of drug testing. There was at least a five-day interval between successive experiments with any rat after IT administration of a drug. Each animal received a total of three injections.

\section{Drug administration}

Drugs were administered intrathecally with a microinjection syringe over a 60 -sec interval in a volume of 10 $\mu \mathrm{L}$, followed by a $10-\mu \mathrm{L}$ flush. The drugs were given in a blind fashion. The evaluation of reversal of tactile allodynia and dose $\left(\mathrm{ED}_{50}\right)$ estimated to produce $50 \%$ maximal possible effect (\%MPE) of each drug was conducted with carbachol chloride and clonidine $\mathrm{HCl}$. Doses of $0.3,1,3$, and $10 \mu \mathrm{g}$ were injected for carbachol and $1,3,10$, and $30 \mu \mathrm{g}$ for clonidine. Drug combinations were given concurrently because the times of peak effect of IT carbachol and clonidine coincide. To administer equieffective doses, double doses of each $\mathrm{ED}_{50}$ for carbachol or clonidine and the sum of each $\mathrm{ED}_{50}$ for the combination were administered. All drugs were dissolved in $0.9 \%$ sodium chloride solution. Animals were given a five-day rest period between drug injections to minimize the possibility of development of tolerance and to eliminate the residual effects of a drug. 
TABLE I ED $\mathrm{ED}_{5}(\mu \mathrm{g})$ and 95\% CI for intrathecally administered carbachol, clonidine, and their combination

\begin{tabular}{llllll}
\hline Agent & $\begin{array}{l}\text { Carbachol } \\
\text { fraction of } E D_{50}\end{array}$ & $\begin{array}{l}\text { Component } \\
\text { intrathecal dose }(\mu g)\end{array}$ & $\begin{array}{l}\text { Clonidine } \\
\text { fraction of } E D_{50}\end{array}$ & $\begin{array}{l}\text { Component } \\
\text { intrathecal dose }(\mu g)\end{array}$ & $\begin{array}{l}\text { Sum of } \\
E D_{50} \text { fractions }\end{array}$ \\
\hline Carbachol & 1.00 & $\begin{array}{l}0.44 \\
(0.2-0.95)\end{array}$ & - & - & 1.00 \\
Clonidine & - & -- & 1.00 & 0.58 & 1.00 \\
$\begin{array}{l}\text { Carbachol }+ \\
\text { Clonidine }\end{array}$ & 0.13 & 0.056 & 0.13 & $0.074-2.81)$ & 0.26 \\
\hline
\end{tabular}

$\mathrm{ED}_{5}=50 \%$ effective dose; $\mathrm{CI}=$ confidence interval.

TABLE II Incidence of side effects after intrathecal carbachol, clonidine, and their combination

\begin{tabular}{|c|c|c|c|c|c|}
\hline \multirow[t]{2}{*}{ Agent } & \multirow[t]{2}{*}{ Dose (ug) } & \multirow[t]{2}{*}{$n$} & \multicolumn{3}{|c|}{ Side effects (\%) } \\
\hline & & & Motor weakness & Sedation & Urination \\
\hline \multirow[t]{4}{*}{ Carbachol } & 0.3 & 6 & - & - & - \\
\hline & 1 & 6 & -- & $1(17)$ & $1(17)$ \\
\hline & 3 & 6 & $2(33)$ & $3(50)$ & $3(50)$ \\
\hline & 10 & 6 & $3(50)$ & $4(67)$ & $4(67)$ \\
\hline \multirow[t]{4}{*}{ Clonidine } & 1 & 6 & -- & -- & -- \\
\hline & 3 & 6 & -- & $1(17)$ & $2(33)$ \\
\hline & 10 & 6 & $2(33)$ & $4(67)$ & $5(83)$ \\
\hline & 30 & 5 & $2(40)$ & $5(100)$ & $5(100)$ \\
\hline Carbachol & $0.03+0.04$ & 5 & - & -- & -- \\
\hline \multirow[t]{3}{*}{ + Clonidine } & $0.06+0.08$ & 5 & $1(20)$ & $2(40)$ & $1(20)$ \\
\hline & $0.11+0.15$ & 5 & l (20) & $3(60)$ & $2(40)$ \\
\hline & $0.22+0.29$ & 5 & $2(40)$ & $4(80)$ & $3(60)$ \\
\hline
\end{tabular}

$n=$ number of rats.

\section{Behavioural measures}

Behavioural testing was performed at the same time during the day. To undertake the measurements of a tactile threshold, the rats were placed in an individual plastic cage with a wire mesh bottom. After $20 \mathrm{~min}$, the tactile threshold was measured by applying a von Frey hair to the midplantar surface of the hindpaw ipsilateral to the nerve injury until a positive sign for pain behaviour was elicited. According to the method described by Chaplan et al., ${ }^{13}$ a series of eight calibrated fine von Frey filaments $(0.40,0.70,1.20,2.00$, $3.63,5.50,8.50$, and $15.1 \mathrm{~g}$ ) was presented serially to the lesioned hindpaw in ascending order of strength with sufficient force to cause slight bending against the paw where it was held for six seconds. A brisk withdrawal or paw flinching was considered a positive response, in which case the next filament tested was the next lower force. In the absence of such response, the next filament tested was the next greater force. In the absence of a response at $15 \mathrm{~g}$ pressure, the animal was assigned this cutoff value. The tactile stimulus producing a $50 \%$ likelihood of withdrawal was deter- mined by using the up-down method described by Chaplan et al. ${ }^{13}$ Measurements were taken before and 15 min after an IT dose of each drug and thereafter at $30,45,60,90,120$, and $180 \mathrm{~min}$. Side effects were assessed simply by observing for sedation, urination, and motor weakness. After drug injection, general posture and ambulation were noted. Severe sedation was defined as a significant decrease in spontaneous activity and a loss of the orienting response to light touch stimulation. Motor weakness was evaluated by observing the righting and placing/stepping reflexes, weight bearing, and ambulation.

\section{Experimental paradigm}

The first series of experiments defined the doseresponse curves of intrathecally administered carbachol and clonidine from the \%MPE. The data are reported for the peak effect. In the second series of experiments, $\mathrm{ED}_{50}$ fractions of each drug were administered concurrently to establish the $\mathrm{ED}_{50}$ of the carbachol-clonidine combination. 


\section{Isobolographic and fractional analyses}

To determine whether the drug interaction between carbachol and clonidine is additive or synergistic, an equal dose ratio isobolographic analysis was performed using the method of Tallarida and Murray. ${ }^{14}$ $\mathrm{ED}_{50}$ was defined separately for each drug. Fractions of the $\mathrm{ED}_{50}$ of each drug $(1 / 2,1 / 4,1 / 8$, and $1 / 16$ $\mathrm{ED}_{50}$ for carbachol-clonidine study) were then administered concurrently, and the $\mathrm{ED}_{50}$ of the total dose of the mixture was determined. The $\mathrm{ED}_{50}$ doses of the individual drugs given in combination were calculated from the dose ratio in our study. The theoretical additive dose combination was calculated by the method described by Tallarida et al. ${ }^{14,15}$ The experimentally derived values were determined as described above. The theoretical additive point lies on a line connecting the $\mathrm{ED}_{50}$ values of the individual drugs and experimental values that lie below and to the left of this additive line are considered to be synergistic, whereas values that lie above and to the right of the line demonstrate an antagonistic interaction.

To obtain a value for describing the magnitude of the interaction, a total fraction value was calculated. The $\mathrm{ED}_{50}$ values of the drug given alone were assigned the number 1 . Then, total fraction $=\left(\mathrm{ED}_{50}\right.$ dose of carbachol in combination $/ \mathrm{ED}_{50}$ value for carbachol alone $)+\left(\mathrm{ED}_{50}\right.$ dose of clonidine in combination $/ \mathrm{ED}_{50}$ value for clonidine alone). Values near 1 indicate an additive interaction, and values less than 1 imply a synergistic interaction. ${ }^{16}$

\section{Data analysis and statistics}

The peak effect observed in each rat after drug delivery was recorded. This peak drug effect was then used to calculate a $\% \mathrm{MPE}$, and these data were used to plot a \%MPE $v s$ log dose curve. Withdrawal threshold data from von Frey hair testing were obtained as the actual threshold in grams and were converted to \%MPE using the formula: \%MPE for antiallodynia $=($ [postdrug threshold - baseline threshold] / [15 g - baseline threshold]) x 100. The cutoff value was defined as a stimulus intensity of $15 \mathrm{~g}$ for the tactile threshold (i.e., $\% \mathrm{MPE}=100$ ).

Analysis of the dose-response curves and statistics were obtained by using the pharmacologic software programs of Tallarida and Murray ${ }^{3}$ and included calculation of the $\mathrm{ED}_{50}$ values and their $95 \%$ confidence intervals (CIs). Dose-response and time course data are presented graphically as mean $\% \mathrm{MPE} \pm \mathrm{SEM}$.

Statistical analysis of drug interactions was conducted according to the procedures of Tallarida and Murray. ${ }^{14}$ The difference between the theoretical additive point and the experimentally derived $\mathrm{ED}_{50}$ was compared using Student's t test. Statistical comparisons of the difference between the agonistic effect and the antagonistic effect were performed by either unpaired $t$ test or Mann-Whitney Rank Sum test. Values of $P<$ 0.05 were considered statistically significant.

Results

\section{Baseline response characteristics}

After spinal nerve ligation, all rats displayed normal general behaviour and weight gain. Tactile allodynia usually developed within one week after surgery and lasted for six to eight weeks. However, onset time, duration, and magnitude of tactile allodynia varied. After catheter implantation in the animals with a nerve ligation, the threshold for evoking withdrawal was in the range of $1-4 \mathrm{~g}$ for all rats.

\section{Antiallodynic effects of IT agonists}

The effect of various IT doses of the two agonists over time was similar in general. The maximal effect occurred within $30 \mathrm{~min}$ for all doses tested in each group. The time course of the carbachol-clonidine combination was similar. Although not indicated here, there were a dose dependent increase in the magnitude and a dose dependent prolongation in the duration of the effect. A somewhat longer antiallodynic effect was observed after the IT injection of carbachol $(10 \mu \mathrm{g})$ and clonidine $(30 \mu \mathrm{g})$. IT administration of carbachol, clonidine and combination of carbacholclonidine resulted in a dose-dependent increase in antiallodynic effect, as illustrated in Figure 1. Although not parallel, the slope of the combination group was shifted to the left compared with that of each agonist. All doses of carbachol and clonidine produced antiallodynic responses without any signs of severe motor weakness.

\section{Drug interaction}

The $\mathrm{ED}_{50}$ values and slopes (95\% CIs) are as follows: $0.44(0.2-0.95) \mu \mathrm{g}$ and $39(24-54)$ for carbachol $(n=24), 0.58(0.12-2.8) \mu \mathrm{g}$ and 31 (16-47) for clonidine $(n=23)$, and $0.13(0.09-0.18) \mu \mathrm{g}$ and 84 (52-116) for the combination $(n=20)$.

Using isobolographic analysis, a synergistic antiallodynic effect was found between IT carbachol and clonidine (Figure 2). The antiallodynic effect of the carbachol-clonidine combination was significantly greater than the calculated additive effect $(P<0.05)$. The experimentally determined mixture $\mathrm{ED}_{50}( \pm$ SEM) was $0.056 \mu \mathrm{g}( \pm 0.009)$ for carbachol and $0.074 \mu \mathrm{g}( \pm 0.012)$ for clonidine. The theoretical additive $\mathrm{ED}_{50}$ was calculated to be $0.22 \mu \mathrm{g}( \pm 0.19)$ for carbachol and $0.29 \mu \mathrm{g}( \pm 0.25)$ for clonidine. 


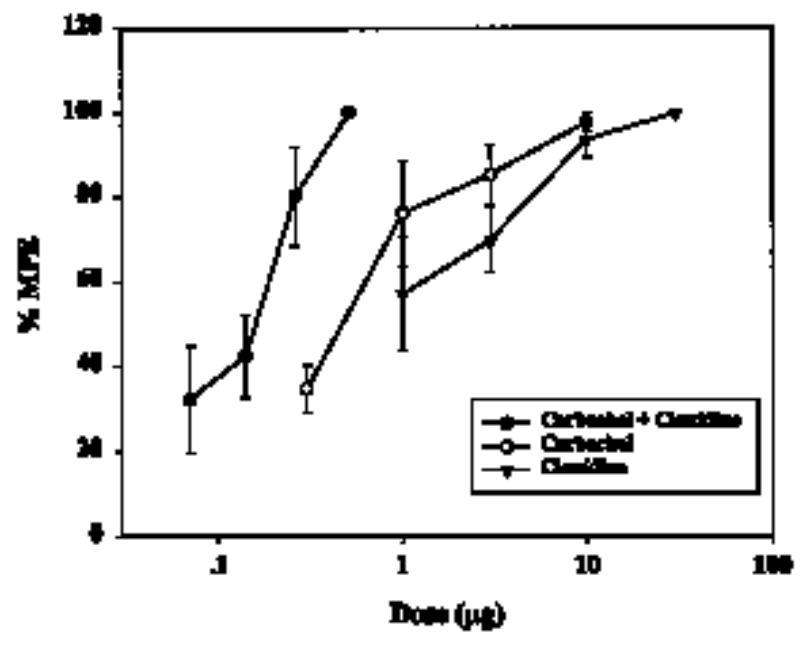

FIGURE 1 Dose-response curves plotting \% maximal possible effect (MPE) for the antiallodynia of carbachol, clonidine, and in combination. The points are expressed as mean \pm SEM of five or six rats. Doses $(\mu \mathrm{g})$ are represented logarithmically on the $\mathrm{X}$ axis and \%MPE is represented on the $\mathrm{Y}$ axis.

According to the fractional method used here, total fraction for the carbachol-clonidine combination was 0.26 and the total fractional value less than 1 indicated a synergistic interaction (Table I).

\section{Side effects}

A number of rats in all groups displayed a mild to moderate motor weakness, sedation and frequent urination, but no severe motor weakness or sedation was observed in any rat. The incidence and magnitude of side effects were generally reduced when drugs were combined (Table II). After the IT injection of either $10 \mu \mathrm{g}$ carbachol or $30 \mu \mathrm{g}$ clonidine, a moderate motor weakness was observed in five rats (three in the carbachol and two in the clonidine group) and the residual

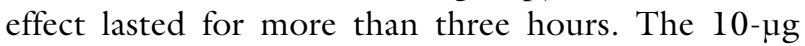
dose of carbachol was also associated with transient agitation, salivation, and hindlimb weakness. No other adverse effects were noted.

\section{Discussion}

After peripheral nerve injury, a low intensity mechanical stimulus can evoke prominent pain behaviour, mediated by the activation of low threshold mechanoreceptors subserved by large, myelinated afferent fibres. ${ }^{17} \mathrm{~A}$ previous study suggested that muscarinic stimulation of critical spinal sites resulted in the activation of local lumbar cholinergic circuits that

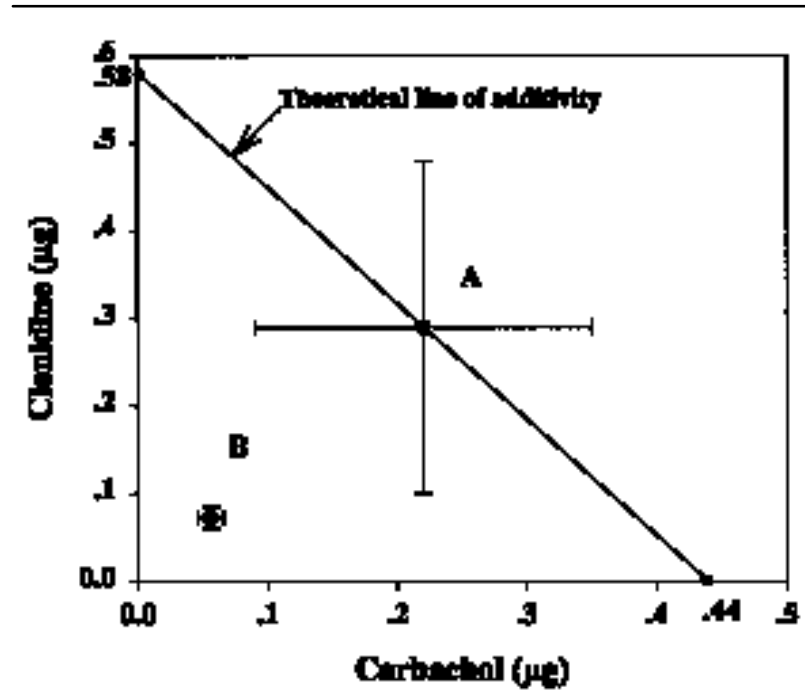

FIGURE 2 The isobolographic plot for the interaction between intrathecal carbachol and clonidine. The $\mathrm{ED}_{50}$ values (and $\pm \mathrm{SEM}$ ) for carbachol and clonidine are plotted on the $\mathrm{X}$ and $\mathrm{Y}$ axes, respectively. The diagonal line connecting these two $\mathrm{ED}_{50}$ points is the theoretical additive line. The theoretical additive $\mathrm{ED}_{50}$ point (A) is calculated from the $\mathrm{ED}_{50}$ values and $95 \%$ confidence intervals of each agent. The experimental $\mathrm{ED}_{50}$ point (B) for the combination of drugs lies below and to the left side of this additive line and is considered to be synergistic.

might modulate the local transmission of the afferent allodynic information. ${ }^{8}$ Considerable evidence exists that the muscarinic cholinergic system of the lumbar spinal cord is intrinsic ${ }^{18,19}$ and that the cholinergic innervation of the intermediolateral cell column (IML) is from a source intrinsic to the spinal cord. ${ }^{19,20}$

A recent study by Pan et al., ${ }^{7}$ found that spinally released acetylcholine plays a role in the antiallodynic effect of IT clonidine in neuropathic pain. Yaksh et al. reported that spinal -2 receptor agonists inhibit preganglionic neurons and diminish sympathetic outflow, resulting in their antiallodynic action. He emphasized that the site of the antiallodynic action of spinal -2 agonists is located at the level of the spinal preganglionic neurons and that the spinal effects are not likely to be mediated by a peripheral redistribution of the drug. ${ }^{6}$ While -2 receptor sites have been localized both pre- and postsynaptically, there is some evidence that the effect of clonidine in other regions of the IML may be postsynaptic (i.e., not via receptors on nerve terminals). ${ }^{21}$ Seybold and Elde suggested a location of 2 receptors on nerve fibres and, in general, the location of these densities is significant over the IML and over 
sympathoadrenal neurons in particular. ${ }^{22}$ Muscarinic receptor sites were also high in the IML, although they appeared less densely distributed than binding sites in the ventral horn. The activity in the preganglionic fibres is determined at the level of their cell bodies in IML by the integration of synaptic inputs.

We hypothesized that the antiallodynic effects of the coadministered drugs at the spinal level were mediated by these independent receptor systems. There was a reduction in dose for either drug, suggesting a synergistic interaction. It is possible, howev$\mathrm{er}$, that the enhanced effect resulted from a decreased clearance, changes in agonist affinity, and functional interactions. Although redistribution of the drugs present was not examined, we do not believe that our results reflect an altered clearance of either drug because there was no apparent increase in the duration of action in the combination group. With regard to changes in agonist affinity, Kenakin described that increases in slopes might reflect increased efficacy. ${ }^{23} \mathrm{In}$ our experiments the slope was increased in the combination group and was shifted to the left (Figure l). If a functional receptor interaction had existed, we would have anticipated that the appearance of motor weakness, urination or sedation would have been similarly enhanced. Although there exists a synergism in the allodynic component, failure to observe such an enhancement of side effects likely excludes a facilitation of the receptor interaction (Table II). In spite of the above possible explanations, the exact mechanisms to explain synergism are not known yet.

Another possible mechanism might be the cholinomimetic effects produced by clonidine and the presence of muscarinic receptors in the dorsal horn of the spinal cord. A putative explanation for the interaction between spinal -2 adrenergic and cholinergic spinal tracts is the existence of a cholinergic interneuron located in the dorsal horn. ${ }^{24}$ However, the organization of these interactions is not still known. Clonidine increases cerebrospinal fluid acetylcholine levels at the time of peak analgesia, an effect potentiated by cholinesterase inhibitors and blocked by -2 adrenoceptor antagonists. ${ }^{24}$ Likewise, this study supports the existence of an antiallodynic interaction between -2 adrenergic and cholinergic mechanisms at the spinal level.

Both surgical and systemic chemical sympathectomy have been reported to abolish the increased threshold for tactile allodynia, ${ }^{4,5}$ whereas Lavand'homme et al. reported that neither chemical nor surgical sympathectomy altered mechanical allodynia in the nerve ligation model. ${ }^{25} \mathrm{We}$ assumed that this spinal ligation injury is a model for sympathetically mediated pain and the interaction may in part involve the sympathetic nervous sys- tem. A number of studies have questioned whether the model of neuropathic pain described by Kim and Chung is truly one of sympathetically mediated pain. ${ }^{25,26}$ Further studies are needed on this issue.

Although not quantified systematically, IT carbachol or clonidine resulted in a dose-dependent reduction in spontaneous activity. In the present study, some of the rats showed mild to moderate side effects, but none showed severe motor weakness and sedation. IT doses of $20 \mu \mathrm{g}$ and higher of carbachol have been reported to cause severe hindpaw motor impairment in the animals. ${ }^{27}$ IT carbachol seems to produce less adverse effects than neostigmine. The reason for the lack of side effects of carbachol compared to neostigmine may be related to carbachol's relative lack of nicotinic effect. ${ }^{11}$ The effect on motor performance is particularly crucial in studies of spinal cholinomimetic drugs because of the existence of cholinergic pathways in the -2 motor neuron area of the spinal cord. ${ }^{20,22}$ The major side effects of clonidine are sedation, related to its supraspinal redistribution, ${ }^{28}$ and hypotension mediated by a spinal action. ${ }^{29}$ That of carbachol is motor weakness, ${ }^{27}$ supported by the distribution of muscarinic receptor sites in the ventral horn. ${ }^{20}$ However, IT clonidine at high doses can produce hindlimb motor weakness and sedation. Yaksh et al. reported that weakness and sedation are not likely to be related to clonidine's antiallodynic action, due to the lack of antiallodynic effect after intracerebro-ventricular administration and its conspicuous antiallodynic effect at doses where hindlimb weakness can not be detected. ${ }^{6}$ We considered that side effects in animal studies are difficult to evaluate without blinded objective scoring and quantification. Therefore, we simply assessed motor dysfunction by checking only the presence of each component. In Table II there are inadequate data to determine the degree of interaction of these drugs for side effects. Although there was a synergistic interaction for antiallodynia, the incidence of sedation in the combination group (9 of 20) was almost the same as that of carbachol (8 of 24) or clonidine (10 of 23 ) alone.

In conclusion, intrathecally administered carbachol or clonidine produced dose-dependent antiallodynia without any severe side effect. Further, our results suggest that the antiallodynic effect of IT carbachol, when combined with IT clonidine, is synergistic in a rat model of nerve ligation injury.

\section{References}

1 Kim SH, Chung JM. An experimental model for peripheral neuropathy produced by segmental spinal nerve ligation in the rat. Pain 1992; 50: 355-63. 
2 Sheen K, Chung JM. Signs of neuropathic pain depend on signals from injured nerve fibers in a rat model. Brain Res 1993; 610: 62-8.

3 Kim KJ, Yoon YW, Chung JM. Comparison of three rodent neuropathic pain models. Exp Brain Res 1997; 113: 200-6.

$4 \mathrm{Kim}$ SH, Na HS, Sheen K, Chung JM. Effects of sympathectomy on a rat model of peripheral neuropathy. Pain 1993; 55: 85-92.

5 LoPachin RM, Rudy TA. The effects of intrathecal sympathomimetic agents on neural activity in the lumbar sympathetic chain of rats. Brain Res 1981; 224: 195-8.

6 Yaksh TL, Pogrel JW, Lee YW, Chaplan SR. Reversal of nerve ligation-induced allodynia by spinal alpha-2 adrenoceptor agonists. J Pharmacol Exp Ther 1995; 272: 207-14.

7 Pan H-L, Chen S-R, Eisenach JC. Intrathecal clonidine alleviates allodynia in neuropathic rats. Anesthesiology 1999; 90: 509-14.

8 Hwang J-H, Hwang K-S, Leem J-K, Park P-H, Han S$M$, Lee $D-M$. The antiallodynic effects of intrathecal cholinesterase inhibitors in a rat model of neuropathic pain. Anesthesiology 1999; 90: 492-9.

9 Hartvig P, Gillberg PG, Gordh T Jr, Post C Cholinergic mechanisms in pain and analgesia. Trends Pharmacol Sci 1989; 10: 75-9.

10 Lavand'homme PM, Eisenach JC. Sex differences in cholinergic analgesia II. Differing mechanisms in two models of anesthesia. Anesthesiology 1999; 91: 1455-61.

11 Abram SE, O'Connor TC. Characteristics of the analgesic effects and drug interactions of intrathecal carbachol in rats. Anesthesiology 1995; 83: 844-9.

12 Yaksh TL, Rudy TA. Chronic catheterization of the spinal subarachnoid space. Physiol Behav 1976; 17: 1031-6.

13 Chaplan SR, Bach FW, Pogrel JW, Chung JM, Yaksh TL. Quantitative assessment of tactile allodynia in the rat paw. J Neurosci Methods 1994; 53: 55-63.

14 Tallarida RJ, Murray RB. Manual of Pharmacologic Calculations with Computer Programs, 2nd ed. New York: Springer-Verlag, 1987.

15 Tallarida RJ, Porreca F, Cowan A Statistical analysis of drug-drug and site-site interactions with isobolograms. Life Sci 1989; 45: 947-61.

16 Berenbaum MC. Synergy, additivism, and antagonism in immunosuppression. A critical review. Clin Exp Immun 1977; 28: 1-18.

17 Campbell JN, Raja SN, Meyer RA, Mackinnon SE. Myelinated afferents signal the hyperalgesia associated with nerve injury. Pain 1988; 32: 89-94.

18 Sherriff FE, Henderson Z, Morrison JFB. Further evidence for the absence of a descending cholinergic pro- jection from the brainstem to the spinal cord in the rat. Neurosci Lett 1991; 128: 52-6.

19 Barber RP, Phelps PE, Houser CR, Crawford GD, Salvaterra PM, Vaughn JE. The morphology and distribution of neurons containing choline acetyltransferase in the adult rat spinal cord: an immunocytochemical study. J Comp Neurol 1984; 229: 329-46.

20 Kayaalp SO, Neff NH. Regional distribution of cholinergic muscarinic receptors in spinal cord. Brain Res 1980; 196: 429-36.

21 Connor HE, Finch L. Postsynaptic spinal -adrenoreceptors mediate effects of intrathecal clonidine. Eur J Pharmacol 1981; 76: 97-100.

22 Seybold VS, Elde RP. Receptor autoradiography in thoracic spinal cord: correlation of neurotransmitter binding sites with sympathoadrenal neurons. J Neurosci 1984; 4: 2533-4.

23 Kenakin TP. Pharmacologic Analysis of Drug-receptor Interaction. New York: Raven Press, 1987.

24 Detweiler DJ, Eisenach JC, Tong C, Jackson C A cholinergic interaction in alpha ${ }_{2}$ adrenoceptor-mediated antinociception in sheep. J Pharmacol Exp Ther 1993; 265: 536-42.

25 Lavand'homme P, Pan H-L, Eisenach JC. Intrathecal neostigmine, but not sympathectomy, relieves mechanical allodynia in a rat model of neuropathic pain. Anesthesiology 1998; 89: 493-9.

26 Ringkamp $M$, Eschenfelder S, Grethel EJ, et al. Lumbar sympathectomy failed to reverse mechanical allodyniaand hyperalgesia-like behavior in rats with L5 spinal nerve injury. Pain 1999; 79: 143-53.

27 Gillberg P-G, Gordh T Jr, Hartvig P, Jansson I, Pettersson J, Post $C$ Characterization of the antinociception induced by intrathecally administered carbachol. Pharmacol Toxicol 1989; 64: 340-3.

28 Eisenach JC, Dewan DM, Rose JC, Angelo JM. Epidural clonidine produces antinociception, but not hypotension, in sheep. Anesthesiology 1987; 66: 496-501.

29 Eisenach JC, Tong C Site of hemodynamic effects of intrathecal 2 -adrenergic agonists. Anesthesiology 1991; 74: 766-71. 